\title{
Effects of Alloying Elements on Deformation Mode in Ti-V Based $\beta$ Titanium Alloy System
}

\author{
Hideto OHYAMA and Takashi NISHIMURA ${ }^{11}$
}

Titanium Metals Technology Department, Takasago Plant, Kobe Steel, Ltd., Niihama, Arai-cho, Takasago, Hyogo-ken, 676 Japan. $\quad 1$ I) Iron and Steel Research Laboratories, Kobe Steel, Ltd., Onoe-cho Ikeda, Kakogawa, Hyogo-ken, 675 Japan.

(Received on December 16, 1994; accepted in final form on March 10, 1995)

\begin{abstract}
We have discussed the rule by which the predominant cold deformation modes of metastable $\beta$ phase are governed depending on their chemical compositions through the examinations of the effects of $\mathrm{Sn}, \mathrm{Al}$, and $\mathrm{Zr}$ on $\beta$-quenched and slightly cold rolled microstructures in a Ti- $\mathrm{V}$ based alloy system. It seems in Ti-V binary alloys, that orthorhombic martensitic transformation temperatures Ms and Md are depressed far below room temperature by the athermal $\omega$ phase at over about $15 \% \mathrm{~V}$. Tin and aluminum intrinsically lower these temperatures like vanadium. On the other hand, tin and aluminum simultaneously suppress the athermal $\omega$ phase of Ti-16V to first rise Md and even Ms up to above room temperature, respectively. The deformation mode of $\beta$ phase consequently depends on both the Md temperature and the degree of suppression of the athermal $\omega$ phase formation. Alloys having a Md above room temperature undergo stress-induced martensitic transformation. As for alloys having a Md below room temperature, alloys where the athermal $\omega$ phase is sufficiently suppressed undergo slip, whereas alloys where it is not so done $\{332\}\langle 113\rangle$ twinning. Since aluminum strongly suppresses the athermal $\omega$ formation, increased $\mathrm{Al}$ additions change the deformation mode of Ti-16V from $\{332\}\langle 113\rangle$ twinning to stress-induced martensitic transformation via a quenched $\alpha^{\prime \prime}$ region or that of Ti-16V-4Sn from stress-induced martensitic transformation to slip. On the other hand, since tin does not suppress it so much as aluminum, increased $\mathrm{Sn}$ additions first change the deformation mode of $\mathrm{Ti}-16 \mathrm{~V}$ from $\{332\}\langle 113\rangle$ twinning to stress-induced martensitic transformation but subsequently revive $\{332\}\langle 113\rangle$ twinning again before slip. The deformation mode of Ti- $\mathrm{V}-\mathrm{Al}-\mathrm{S} n$ alloys can be interpreted by superposing the effects of $\mathrm{V}, \mathrm{Al}$, and $\mathrm{Sn}$. Zirconium also depresses martensitic transformation temperatures and $\mathrm{Ti}-14 \mathrm{~V}-6 \mathrm{Zr}$ undergoes stress-induced martensitic transformation. However, Ti-16V based $\mathrm{Zr}$-added alloys undergo $\{332\}\langle 113\rangle$ twinning in the wide range of $Z r$ content because the athermal $\omega$ phase formation is rarely suppressed by zirconium. This interpretation has solved the discrepancy of the transition of deformation modes of $\beta$ titanium alloys.
\end{abstract}

KEY WORDS: $\beta$ titanium alloys; deformation modes; stress-induced martensitic transformation; twinning; slip; athermal $\omega$ phase formation.

\section{Introduction}

The deformation modes of $\beta$ titanium alloys affect both their cold deformability ${ }^{1)}$ and $\alpha$ precipitation behavior. ${ }^{2)}$ From the industrial and metallurgical point of view, it is a very important problem to clarify how the deformation modes are governed by their chemical compositions. In general, unusual $\{332\}\langle 113\rangle$ twinning or stress-induced martensitic transformation takes place in the most unstable alloys. ${ }^{3)}$ The choice of deformation mode is interpreted in terms of the degree of instability of $\beta$ phase. ${ }^{4,5)}$ When alloys are sufficiently $\beta$-stabilized, they are deformed by slip ${ }^{4,5)}$ or $\{112\}\langle 111\rangle$ twinning. ${ }^{6,7)}$ However, few efforts have been made to systematically understand the reason some alloys undergo stressinduced martensitic transformation and others $\{332\}$ $\langle 113\rangle$ twinning even though both categories of alloys are sufficiently unstable.

Recently, Ishiyama and co-workers ${ }^{8)}$ have discussed this subject in connection with the effects of important alloying elements $\mathrm{Al}, \mathrm{Sn}$, and $\mathrm{Zr}$ on the deformation mode of $\beta$ titanium alloys. They have pointed out that tin and aluminum retard athermal $\omega$ phase transformation and move the deformation mode from $\{332\}\langle 113\rangle$ twinning to stress-induced martensitic transformation in $\mathrm{Ti}-16 \mathrm{~V}-\mathrm{Sn}$ and $\mathrm{Ti}-16 \mathrm{~V}-6 \mathrm{Zr}-\mathrm{Al}$ alloy systems, etc., whereas zirconium maintains the $\{332\}\langle 113\rangle$ twinning in $\mathrm{Ti}-16 \mathrm{~V}$ and $\mathrm{Ti}-7 \mathrm{Cr}$ because there is little suppression of athermal $\omega$ phase formation. Additionally, they have suggested that a larger amount of $\mathrm{Sn}$ or $\mathrm{Al}$ depresses the stress-induced martensitic transformation by their solution hardening effect, leading to slip deformation. Their discussion seems to imply that with decreases in the instability of $\beta$ phase, the deformation mode of $\beta$ phase changes from $\{332\}\langle 113\rangle$ twinning to stressinduced martensitic transformation and subsequently to slip in that order. On the other hand, the co-workers have confirmed that $\mathrm{Ti}-20 \mathrm{~V}-3 \mathrm{Sn}^{5)}$ predominantly deforms by $\{332\}\langle 113\rangle$ twinning even though the athermal $\omega$ phase formation must be more heavily suppressed 
by the extra $4 \%$ vanadium $^{9,10}$ ) in this alloy than in a Ti-16V-3Sn alloy belonging to the strain-transformable region. ${ }^{8)}$ Furthermore, we have confirmed, even though by optical microstructural observations only, that $\mathrm{Ti}-16 \mathrm{~V}-10 \mathrm{Sn}$ undergoes mechanical twinning. There is still a problem concerning the alternative of $\{332\}\langle 113\rangle$ twinning and stress-induced martensitic transformation in the most unstable $\beta$ titanium alloys. It is necessary to clarify the rule by which the deformation modes of $\beta$ phase are determined.

Hence, we have studied the roles of main alloying elements $\mathrm{V}, \mathrm{Sn}, \mathrm{Al}$, and $\mathrm{Zr}$ on the deformation mode of $\beta$ phase, using a $\mathrm{Ti}-\mathrm{V}$ based $\beta$ titanium alloy system.

\section{Experimental Procedure}

In this study we examined the effects of $\mathrm{V}, \mathrm{Sn}, \mathrm{Al}$, and $\mathrm{Zr}$ on $\beta$-solution treated or slightly cold rolled microstructures in $\mathrm{Ti}-(10-22) \mathrm{V}-(0-12) \mathrm{Sn}-(0-7) \mathrm{Al}-(0-6) \mathrm{Zr}$ alloys.

Small button ingots were plasma-arc melted in dimensions of about $40 \mathrm{~mm}$ in diameter and $23 \mathrm{~mm}$ in thickness. They were hot-rolled at $1273 \mathrm{~K}$ to a $5 \mathrm{~mm}$ thickness, solution treated at $1273 \mathrm{~K}$ for $0.6 \mathrm{ksec}$, water-quenched, machined to a $4 \mathrm{~mm}$ thickness for descaling, cold-rolled at $75 \%$, solution treated at $1273 \mathrm{~K}$ for $0.6 \mathrm{ksec}$, and water-quenched. Subsequently, small pieces cut from the sheets were cold-rolled at $3 \%$ in order to introduce strain-induced products into the matrices. Vickers hardness was measured for some water-quenched samples. Microstructures of both the undeformed and the cold-rolled samples were observed with a Nomarski optical microscope. Some cold-rolled samples were examined by X-ray diffraction or transmission electron microscopy as well.

\section{Results}

\subsection{Quenched Microstructures}

Figure 1 shows microstructures after water-quenching of $\mathrm{Ti}-\mathrm{V}$ binary alloys with 12 to $15 \% \mathrm{~V}$. The $\beta$ phase of $\mathrm{Ti}-12 \mathrm{~V}$ was completely transformed to orthorhombic $\alpha^{\prime 11-13)}$ or hexagonal $\alpha^{\prime 3)}$ phase. With increasing $\mathrm{V}$ content the martensite phase gradually decreases, and finally disappears at $15 \%$. This shows that $\mathrm{V}$ lowers the martensitic transformation finish temperature Mf. The martensitic transformation start temperature Ms exists between Mf and the upper limit temperature of the strain-transformable range $\mathrm{Md}$. These temperatures $\mathrm{Md}$ and Ms may probably shift in almost the same manner, corresponding to each other. Vanadium should lower these temperatures as well.

Figure 2 shows the microstructural change with $\mathrm{Al}$ content in Ti-16 V based alloys. A small addition of $0.3 \%$ Al promotes $\alpha^{\prime \prime}$ martensitic transformation. An addition of $3 \% \mathrm{Al}$ gives rise to pronounced $\alpha^{\prime \prime}$ phase transformation. On the other hand, additions of 5 to $7 \% \mathrm{Al}$ can completely retain the $\beta$ phase. Maeda and Flower ${ }^{14)}$ have suggested that the $\alpha^{\prime \prime}$ transformation first promoted by a small amount of $\mathrm{Al}$ additions is attributable to the suppression of athermal $\omega$ phase

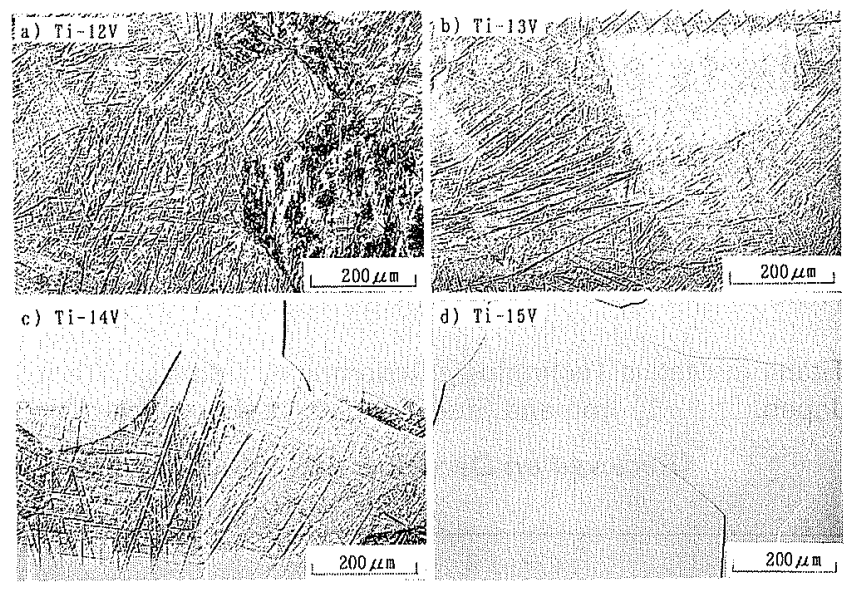

Fig. 1. Quenched microstructures of Ti-V binary alloys with 12 to $15 \% \mathrm{~V}$.

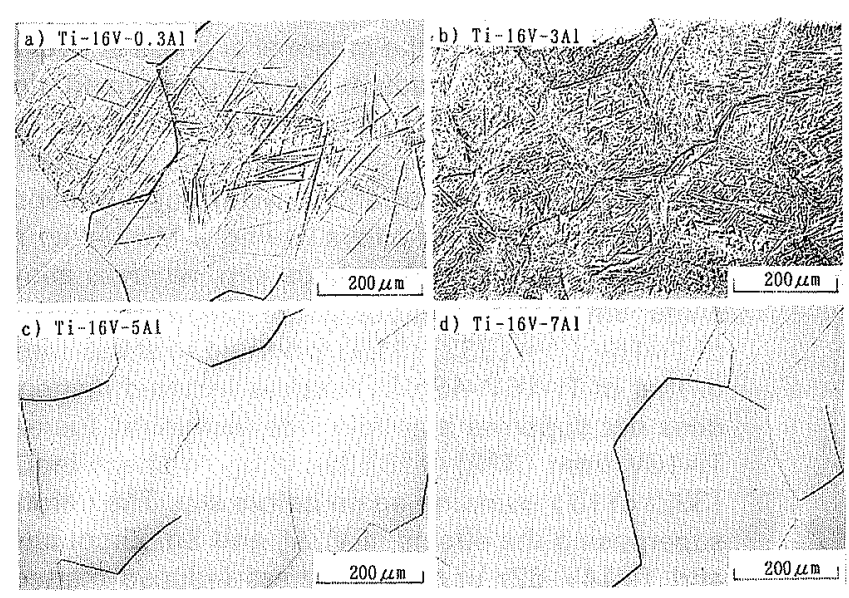

Fig. 2. Microstructural change with $\mathrm{Al}$ content in $\mathrm{Ti}-16 \mathrm{~V}$ based alloys.

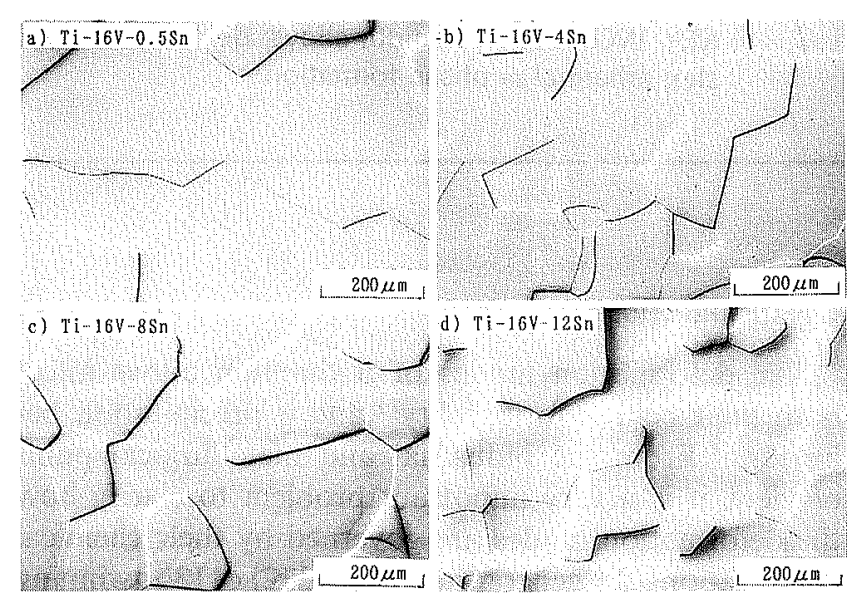

Fig. 3. Quenched microstructures of $\mathrm{Ti}-16 \mathrm{~V}$ based alloys containing 0.5 to $12 \% \mathrm{Sn}$.

formation. Aluminum is expected to lower martensitic transformation temperatures.

Figure 3 shows quenched microstructures of $\mathrm{Ti}-16 \mathrm{~V}$ based alloys containing 0.5 to $12 \% \mathrm{Sn}$. Unlike $\mathrm{Al}$ additions, any percent of $\mathrm{Sn}$ addition never causes the $\alpha^{\prime \prime}$ transformation during quenching in the range from 0.5 to $12 \%$ for $\mathrm{Ti}-16 \mathrm{~V}$. Figure 4 shows quenched microstructures of Ti-16V-1Sn-3Al, Ti-16V-4Sn-1Al, and Ti-16V-4Sn-3Al. An addition of $1 \%$ Sn reduces the $\alpha^{\prime \prime}$ 


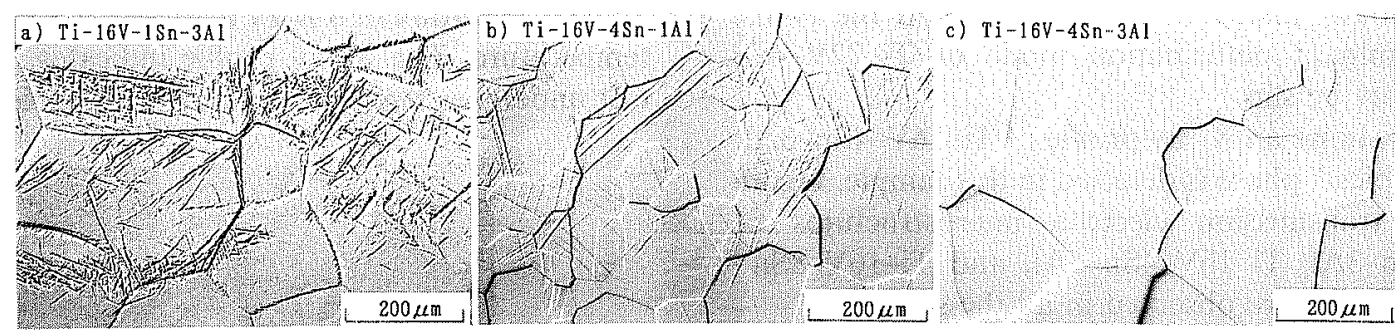

Fig. 4. Quenched microstructures of $\mathrm{Ti}-16 \mathrm{~V}-1 \mathrm{Sn}-3 \mathrm{Al}, \mathrm{Ti}-16 \mathrm{~V}-4 \mathrm{Sn}-1 \mathrm{Al}$, and $\mathrm{Ti}-16 \mathrm{~V}-4 \mathrm{Sn}-3 \mathrm{Al}$.

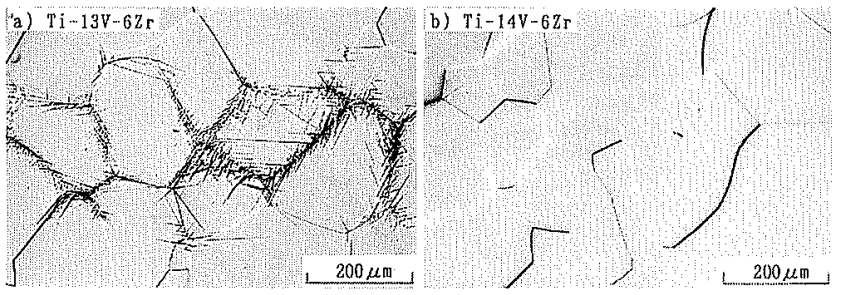

Fig. 5. Quenched microstructures of $\mathrm{Ti}-13 \mathrm{~V}-6 \mathrm{Zr}$ and $\mathrm{Ti}-$ $14 \mathrm{~V}-6 \mathrm{Zr}$

transformation of Ti-16V-3Al. Moreover, an addition of $1 \% \mathrm{Al}$ promotes the $\alpha^{\prime \prime}$ transformation even in Ti-16V-4Sn.

This means that an addition of $4 \%$ Sn suppresses the athermal $\omega$ phase formation less than that of $0.3 \% \mathrm{Al}$ in $\mathrm{Ti}-16 \mathrm{~V}$. The $\beta$ phase is completely retained in $\mathrm{Ti}-16 \mathrm{~V}-4 \mathrm{Sn}-3 \mathrm{Al}$. These facts conclusively prove that tin lowers martensitic transformation temperatures like Al but suppresses the athermal $\omega$ phase formation less than Al.

Figure 5 shows quenched microstructures of Ti-13V$6 \mathrm{Zr}$ and $\mathrm{Ti}-14 \mathrm{~V}-6 \mathrm{Zr}$. As Fig. 1 showed, Ti-13V and Ti-14V partly undergo the $\alpha^{\prime \prime}$ transformation during quenching. On the other hand, the $\alpha^{\prime \prime}$ transformation is depressed by an addition of $6 \% \mathrm{Zr}$. Ishiyama et al. ${ }^{8)}$ have confirmed that zirconium rarely suppresses the athermal $\omega$ phase formation. However, zirconium also lowers Ms.

\subsection{Deformation Modes of Ti-V Base Metastable $\beta$ Alloys}

We have examined stress-induced products of $3 \%$ cold rolled samples for alloys where all $\beta$ phase could be obtained by water-quenching.

Figure 6 shows optical microstructures of $3 \%$ cold rolled samples for Ti-16V-5Al, Ti-16V-7Al, Ti-18V$3 \mathrm{Al}$, and Ti-22V-3Al. Deformation-induced products are clearly observed in all the samples. One of the authors of this paper ${ }^{2)}$ previously reported with the optical microstructural characteristics of slightly deformed $\beta$ titanium alloys, that stress-induced $\alpha^{\prime \prime}$ tends to be produced in groups of martensite plates aligned in parallel by cold rolling, deformation twins are frequently accompanied by the internal twins, and that slip brings about a striated structure of planar slip bands with the localized dislocations. However, these features are typical and it is very difficult to identify the deformation-induced products from the optical microstructural observations. So, we have studied the microstructures by X-ray diffraction or transmission electron microscopy. Figure

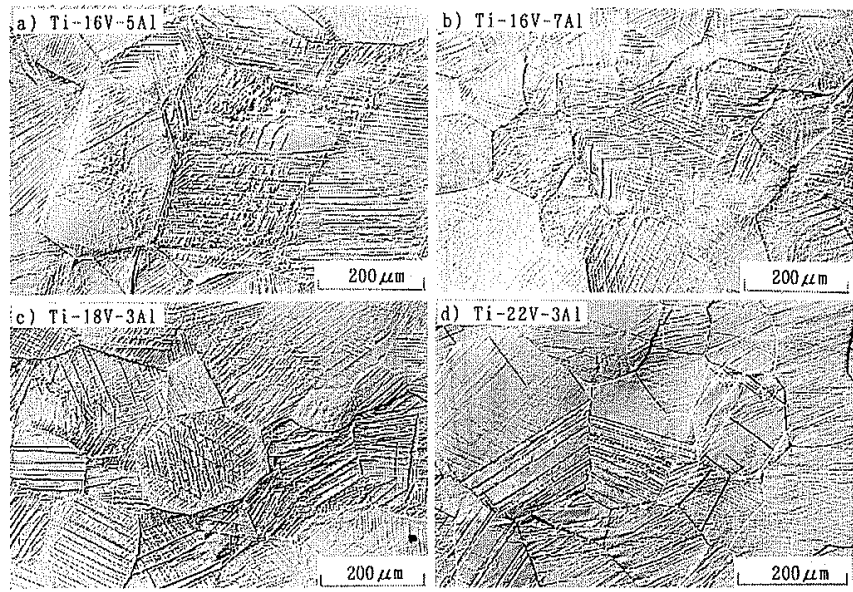

Fig. 6. Optical microstructures of the $3 \%$ cold rolled samples for Ti-16V-5Al, Ti-16V-7Al, Ti-18V-3Al, and $\mathrm{Ti}-22 \mathrm{~V}-3 \mathrm{Al}$

7 shows X-ray profiles of the samples. Orthorhombic $\alpha^{\prime \prime}$ phase is detected in $\mathrm{Ti}-16 \mathrm{~V}-5 \mathrm{Al}, \mathrm{Ti}-16 \mathrm{~V}-7 \mathrm{Al}$, and Ti-18V-3Al. Therefore, the predominant deformation mode of these three alloys is stress-induced martensitic transformation. On the other hand, only diffractions from $\beta$ phase are obtained in Ti-22V-3Al. Figure 8 shows a transmission electron microstructure of the sample of $\mathrm{Ti}-22 \mathrm{~V}-3 \mathrm{Al}$, together with a diffraction pattern commonly obtained from the positions 1,2 , and 3. Dislocations are introduced with a tendency to form slip bands in the matrix. Slip is the predominant deformation mode of $\mathrm{Ti}-22 \mathrm{~V}-3 \mathrm{Al}$.

Figure 9 shows optical microstructures of $3 \%$ cold rolled samples for Ti-16V-8Sn, Ti-16V-12Sn, Ti-20V$4 \mathrm{Sn}$, and Ti-22V-4Sn. In Ti-16V-8Sn mechanical twins occasionally accompanied by internal twins are observed, whereas in $\mathrm{Ti}-16 \mathrm{~V}-12 \mathrm{Sn}$ only vague striations are observed. Transmission electron microstructures of the two samples shown in Figs. 10 and 11 realize that the stress-induced products of $\mathrm{Ti}-16 \mathrm{~V}-8 \mathrm{Sn}$ and $\mathrm{Ti}-$ $16 \mathrm{~V}-12 \mathrm{Sn}$ are $\{332\}\langle 113\rangle$ twins and dislocations, respectively. Figure 12 shows $\mathrm{X}$-ray profiles of the samples for Ti-20V-4Sn and Ti-22ע-4Sn. Diffraction peaks of orthorhombic $\alpha^{\prime \prime}$ phase are unmistakably observed in $\mathrm{Ti}-20 \mathrm{~V}-4 \mathrm{Sn}$. Ti-20V-4Sn undergoes stress-induced martensitic transformation. In the optical microstructure of Ti-22V-4Sn in Fig. 9 a few sharp stress-induced products exist in a vague striated matrix. The $\alpha^{\prime \prime}$ phase is not detected by X-ray analysis, as shown in Fig. 12. Figure 13 shows a transmission electron microstructure of $\mathrm{Ti}-22 \mathrm{~V}-4 \mathrm{Sn}$. The diffraction pattern identifies the sharp products to be $\{112\}\langle 111\rangle$ twins. 
There are many dislocations in addition to the twins. The predominant deformation mode of $\mathrm{Ti}-22 \mathrm{~V}-4 \mathrm{Sn}$ may therefore be slip.

Figure 14 shows an X-ray profile of Ti-16V-4Sn-3Al. Orthorhombic $\alpha^{\prime \prime}$ phase is detected in this sample. Figure 15 shows transmission electron microstructures of Ti-20V-4Sn-3Al, Ti-16V-4Sn-5Al, and Ti-16V-8Sn$3 \mathrm{Al}$. Dislocations are observed in all the samples.

Figures 16 and 17 show an optical microstructure and an X-ray profile of $\mathrm{Ti}-14 \mathrm{~V}-6 \mathrm{Zr}$, respectively. In this
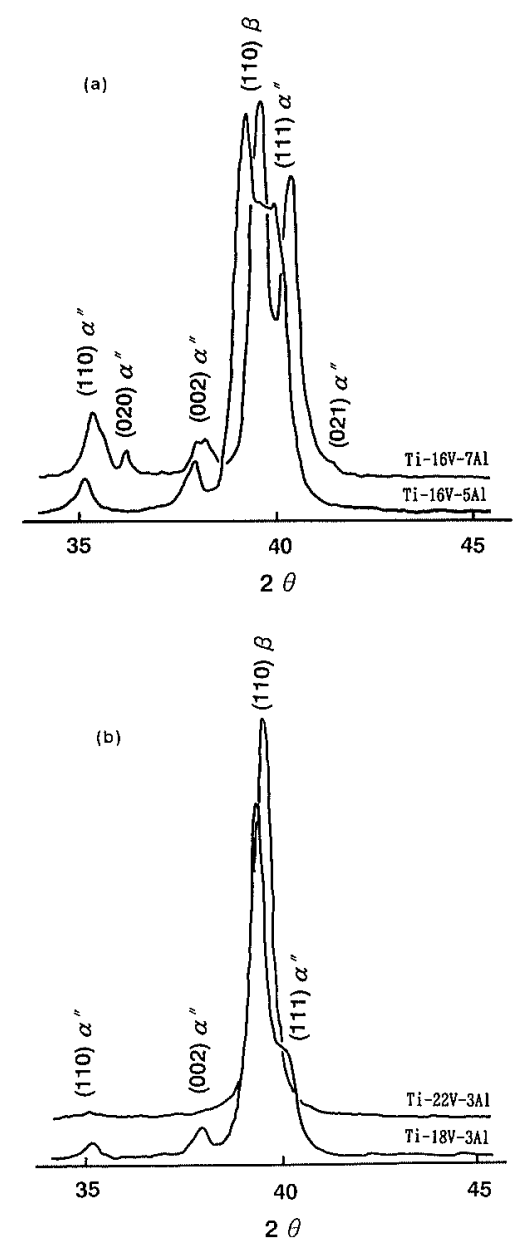

Fig. 7. X-ray profiles of the $3 \%$ cold rolled samples for (a) $\mathrm{Ti}-16 \mathrm{~V}-5 \mathrm{Al}$ and $\mathrm{Ti}-16 \mathrm{~V}-7 \mathrm{Al}$, and (b) Ti-18V-3Al and Ti-22V-3Al. alloy, an addition of $6 \% \mathrm{Zr}$ depresses $\mathrm{Ms}$ to below room temperature. The X-ray profile indicates that $\mathrm{Ti}-14 \mathrm{~V}-$ $6 \mathrm{Zr}$ undergoes stress-induced orthorhombic $\alpha^{\prime \prime}$ transfor-

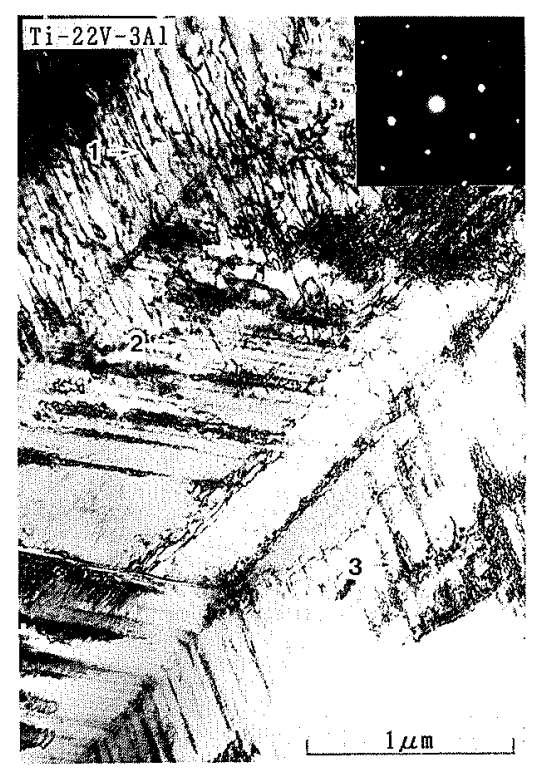

Fig. 8. Transmission electron microstructure of the $3 \%$ cold rolled sample of $\mathrm{Ti}-22 \mathrm{~V}-3 \mathrm{Al}$, together with a diffraction pattern commonly obtained from the positions 1,2 , and 3 .

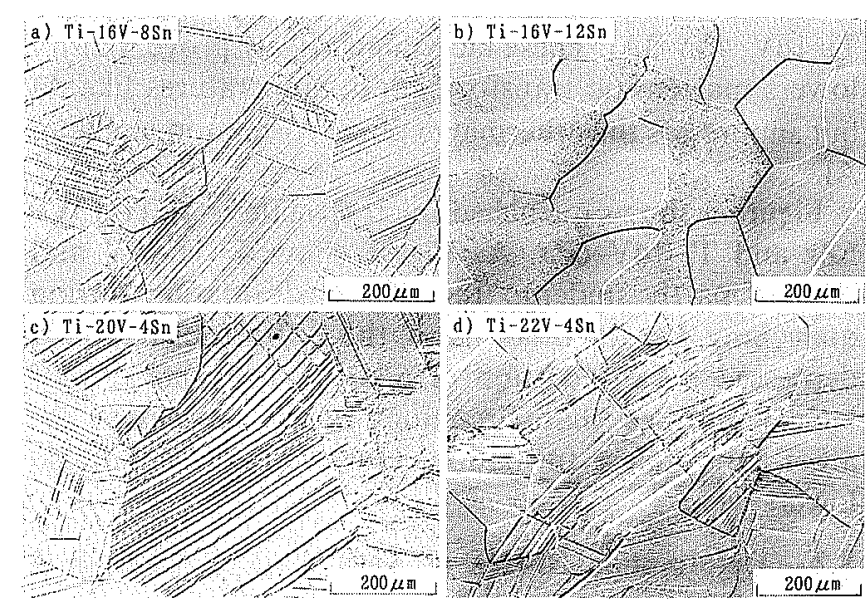

Fig. 9. Optical microstructures of the $3 \%$ cold rolled samples for Ti-16V-8Sn, Ti-16V- $12 \mathrm{Sn}, \mathrm{Ti}-20 \mathrm{~V}-4 \mathrm{Sn}$, and Ti-22V-4Sn.

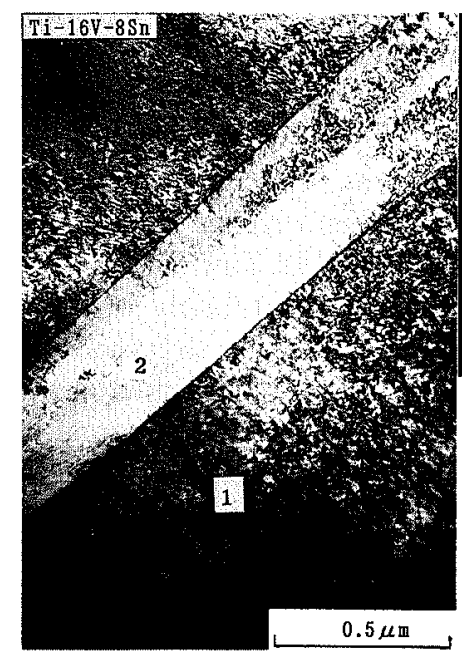

1

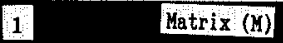

2

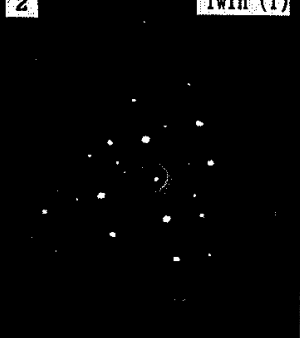

(C) 1995 ISIJ

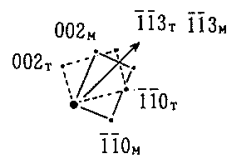

Beam $/ /[\overline{1} 10]_{M} / /[1 \overline{1} 0]_{\mathrm{r}}$
Fig. 10.

Transmission electron microstructure of the $3 \%$ cold rolled sample of $\mathrm{Ti}-16 \mathrm{~V}-8 \mathrm{Sn}$. 
mation.

\subsection{Transition of Deformation Modes}

The occurrence or absence of stress-induced martens-

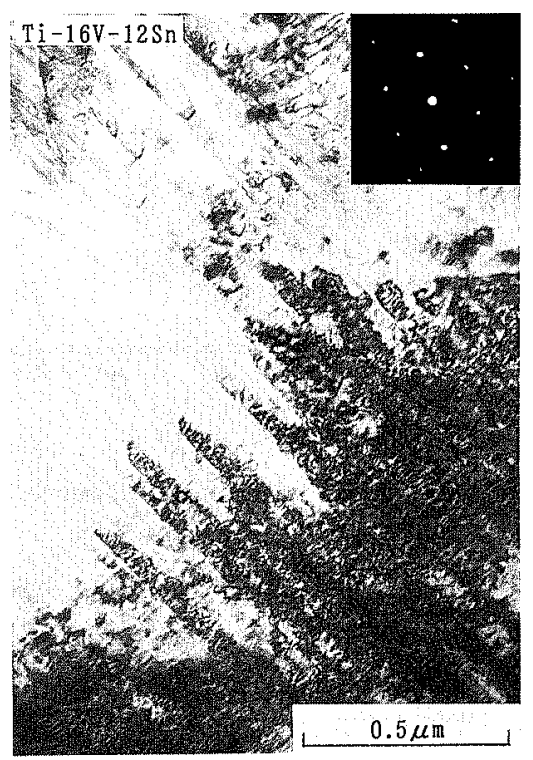

Fig. 11. Transmission electron microstructure of the $3 \%$ cold rolled sample of Ti-16V-12Sn

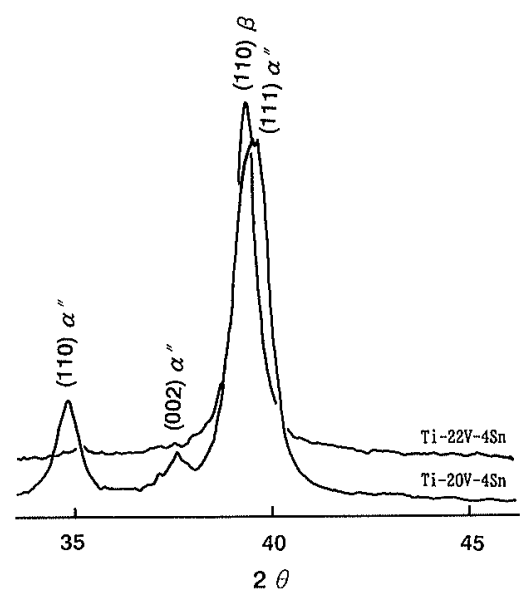

Fig. 12. $\mathrm{X}$-ray profiles of the $3 \%$ cold rolled samples for Ti$20 \mathrm{~V}-4 \mathrm{Sn}$ and $\mathrm{Ti}-22 \mathrm{~V}-4 \mathrm{Sn}$. itic transformation is necessary to correspond to whether or not the alloy has $\mathrm{Md}$ above room temperature. As for the $\mathrm{Ti}-\mathrm{V}$ binary system, alloys deform by $\{332\}\langle 113\rangle$ twinning in the range from 16 to $22 \% \mathrm{~V}$ and by slip for more than $24 \% \mathrm{~V}$ at room temperature. ${ }^{15)}$ As was shown in Fig. 1, Mf, and in turns, Md and Ms may sluggishly decrease with increasing $\mathrm{V}$ content from 12 to $14 \%$. On the other hand, Md is considerably depressed at $16 \% \mathrm{~V}$.

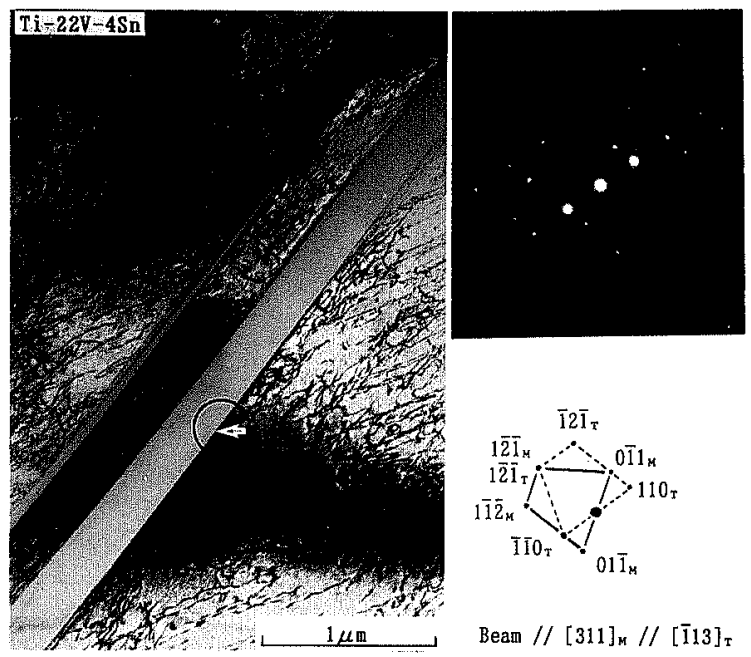

Fig. 13. Transmission electron microstructure of the $3 \%$ cold rolled sample of Ti-22V-4Sn.

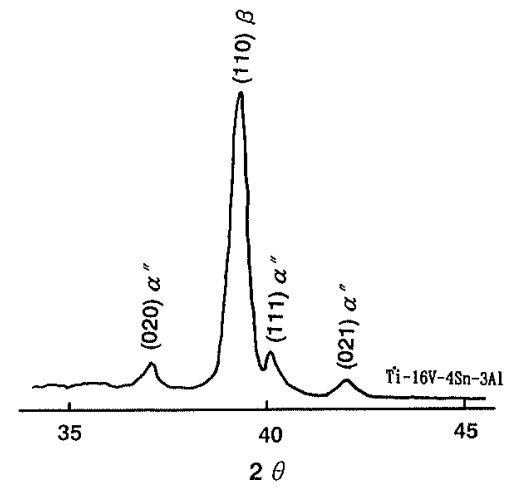

Fig. 14. X-ray profiles of the $3 \%$ cold rolled samples for Ti-16V-4Sn-3Al.
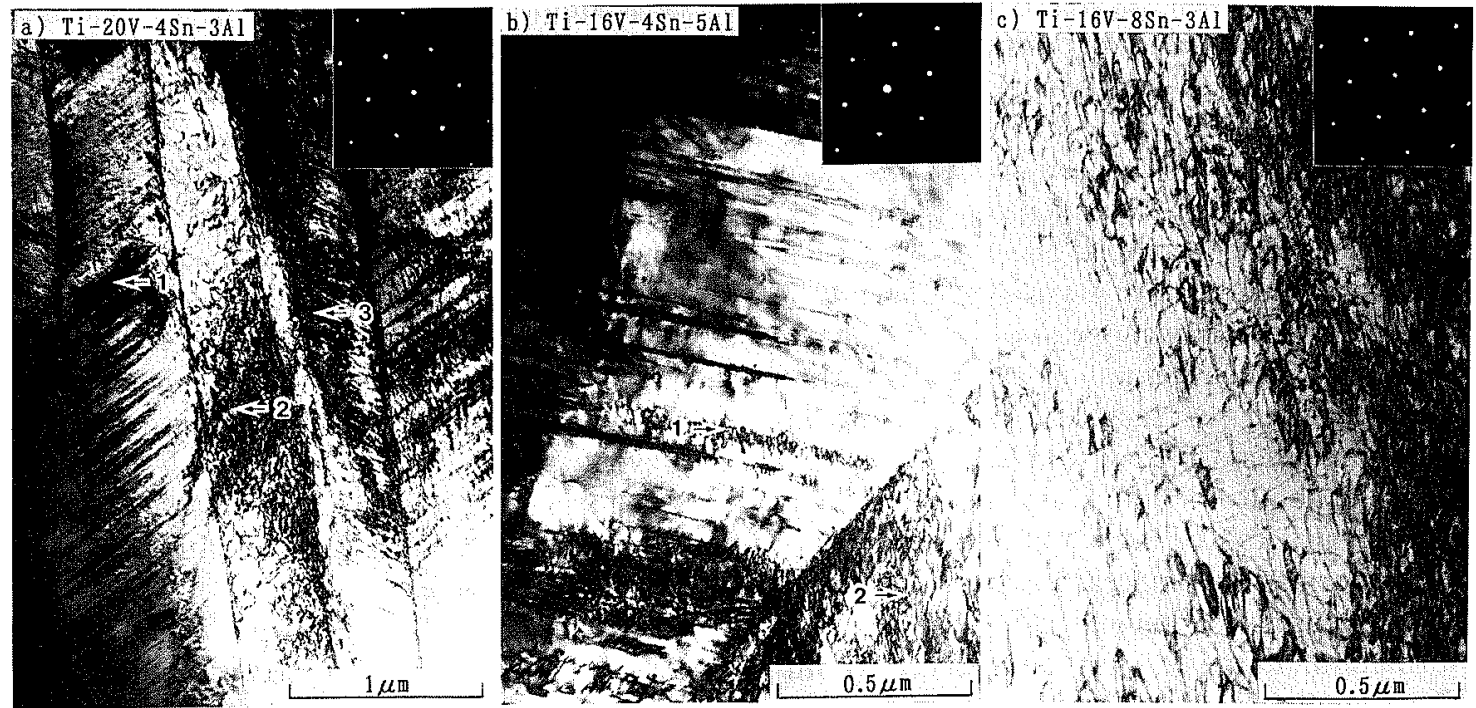

Fig. 15. Transmission electron microstructures of $\mathrm{Ti}-20 \mathrm{~V}-4 \mathrm{Sn}-3 \mathrm{Al}, \mathrm{Ti}-16 \mathrm{~V}-4 \mathrm{Sn}-5 \mathrm{Al}$, and $\mathrm{Ti}-16 \mathrm{~V}-8 \mathrm{Sn}-3 \mathrm{Al}$. 


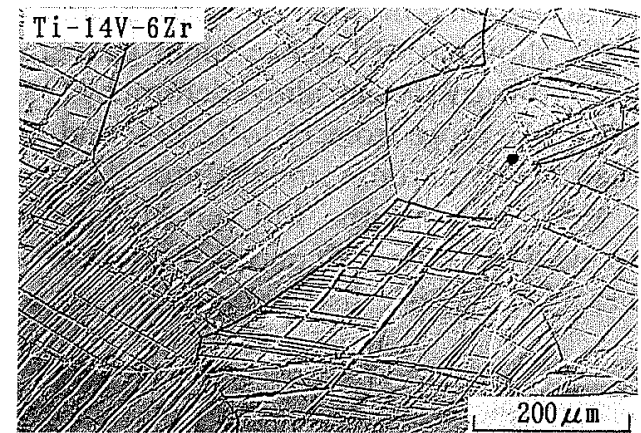

Fig. 16. Optical microstructure of the $3 \%$ cold rolled sample of $\mathrm{Ti}-14 \mathrm{~V}-6 \mathrm{Zr}$.

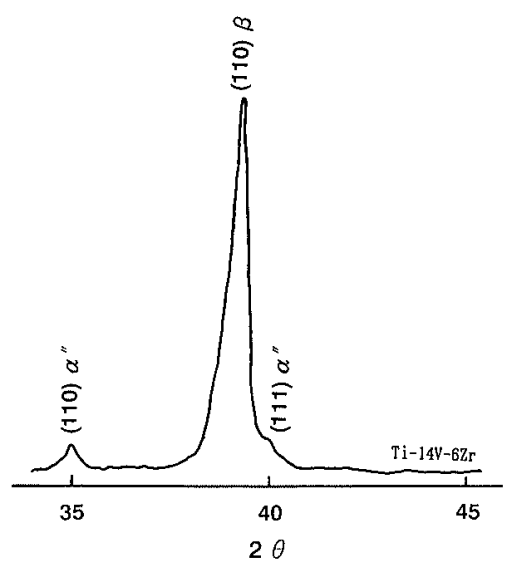

Fig. 17. X-ray profile of the $3 \%$ cold rolled sample of Ti$14 \mathrm{~V}-6 \mathrm{Zr}$.

Hanada et al. ${ }^{15)}$ have reported that $\mathrm{Ti}-16 \mathrm{~V}$ does not undergo stress-induced martensitic transformation but predominantly deforms by $\{332\}\langle 113\rangle$ twinning even at $77 \mathrm{~K}$. This implies that an addition of $16 \% \mathrm{~V}$ depresses $\mathrm{Md}$ down to below $77 \mathrm{~K}$. Compared with the gradual decrease in Mf from 12 to $14 \% \mathrm{~V}$, Ms seems to be remarkably lowered by the increasing $\mathrm{V}$ content from 14 to $16 \%$. Figure 18 shows an X-ray profile of the quenched $\mathrm{Ti}-16 \mathrm{~V}$ alloy where the athermal $\omega$ phase is unmistakably detected. This remarkable depression may therefore be expected to be due to the athermal $\omega$ phase formation, as has also been suggested by Maeda and Flower. ${ }^{14)}$ This presumption is supported by the fact that a small amount of $\mathrm{Al}$ addition promotes the $\alpha^{\prime \prime}$ transformation during quenching. ${ }^{14)}$ Figures 16 and 17 did not show that a Ti-14V based metastable alloy which is $\beta$-stabilized by $6 \% \mathrm{Zr}$ undergoes $\{332\}\langle 113\rangle$ twinning. This does not mean that the $\beta$ phase of Ti$14 \mathrm{~V}-6 \mathrm{Zr}$ is unstable enough to form the athermal $\omega$ phase. ${ }^{5,6,15)}$ Zirconium rarely suppresses the athermal $\omega$ phase formation. ${ }^{8}$ ) The athermal $\omega$ phase formation may not be accelerated so much at $14 \% \mathrm{~V}$. With increases in $\mathrm{V}$ content, therefore, $\mathrm{Md}$ and $\mathrm{Ms}$ are gradually lowered down to about $14 \%$ but are more markedly depressed downwards out of the $V$ content dependence of intrinsic transformation temperatures by the activated athermal $\omega$ phase formation beyond $14 \%$. The athermal $\omega$ phase formation, however, may be reduced gradually. ${ }^{9,10)}$ The athermal $\omega$ phase formation is suppressed enough for slip deformation at about $24 \% .{ }^{15)} \mathrm{Md}$, Ms,

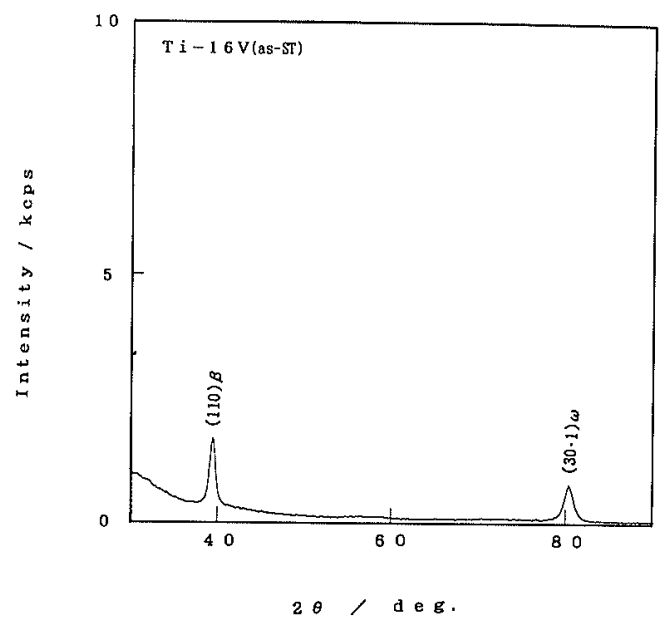

Fig. 18. X-ray profile of the quenched sample of Ti-16V.

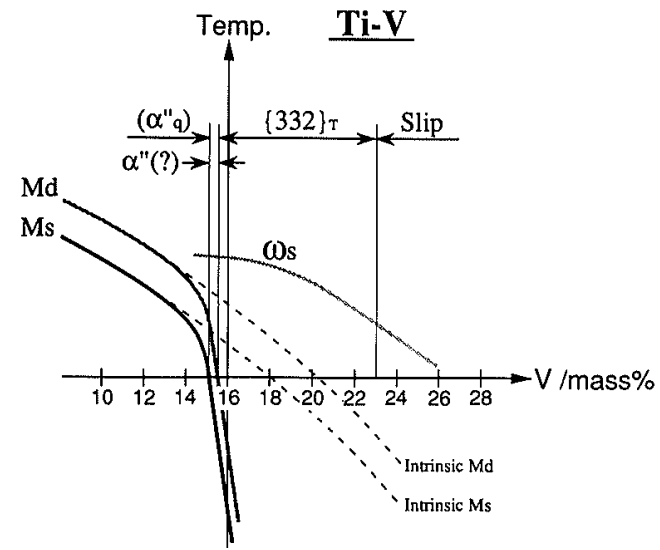

Fig. 19. Schematic changes of Md, Ms, and $\omega$ s with $V$ content in Ti-V binary alloy system. Presumable regions of deformation mode are indicated by question marks (?).

and the athermal $\omega$ phase formation temperature $\omega \mathrm{s}$ may therefore be expected to change with the $\mathrm{V}$ content as Fig. 19 schematically shows. The regions of each predominant deformation mode are also indicated including the quenched $\alpha^{\prime \prime}$ region $\left(\alpha^{\prime \prime} q\right)$. Presumable regions of deformation mode were also indicated in Fig. 19 accompanied by question marks (?), in the same way as the other schematic displays below.

The effects of the other alloying elements on the deformation mode of $\beta$ phase also have to be discussed in terms of both the changes of $\mathrm{Md}$ and $\omega$ s. Komatsu et $a .^{16)}$ and Ikeda et $a l .{ }^{17)}$ have demonstrated from the examinations of resistivity of quenched $\mathrm{Ti}-\mathrm{Fe}$ and $\mathrm{Ti}-\mathrm{Fe}-\mathrm{Al}$ alloys, that the hardness of the alloys lowers with the decreases in the athermal $\omega$ phase. This probably means that the athermal $\omega$ phase plays a role in precipitation hardening. The athermal $\omega$ phase should prevent shear deformation required for martensitic transformation. Even a very small amount of $\mathrm{Al}$ additions promotes martensitic transformation, as was shown in Fig. 2. Supposing that Md or Ms should be depressed downwards out of the intrinsic Md or Ms temperatures when $\omega$ s substantially exists above them and depressed more with increases in the athermal $\omega$ phase, aluminum must suppress $\omega$ s more abruptly than Md or Ms, as 


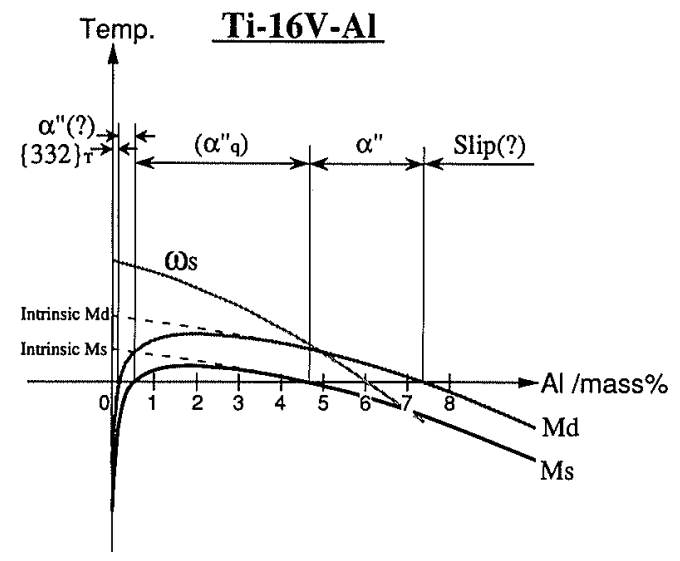

Fig. 20. Schematic changes of $\mathrm{Md}, \mathrm{Ms}$, and $\omega s$ with $\mathrm{Al}$ content in Ti-16V-Al alloy system. Presumable regions of deformation mode are indicated by question marks $(?)$

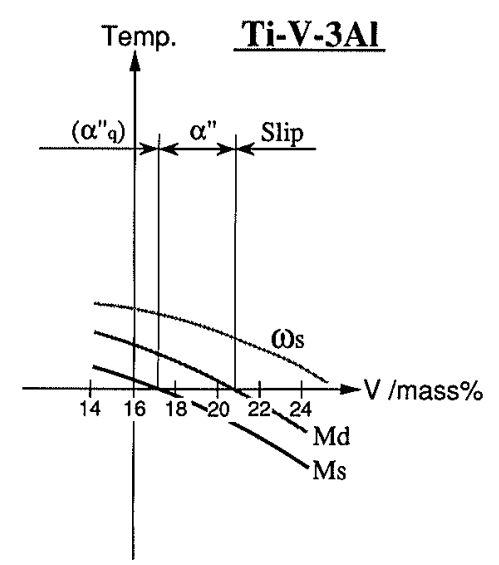

Fig. 21. Schematic changes of Md, Ms, and $\omega$ s with $\mathrm{V}$ content in Ti-V-3Al alloy system.

schematically shown in Fig. 20. At $16 \% \mathrm{~V}$, Md, and Ms are depressed to below $77 \mathrm{~K} .{ }^{15)} \mathrm{A}$ small amount of $\mathrm{Al}$ addition first recovers $\mathrm{Md}$ and $\mathrm{Ms}$ up to above room temperature due to the suppression of the athermal $\omega$ phase formation. ${ }^{14)} \mathrm{Md}$ and $\mathrm{Ms}$, however, may begin to lower intrinsically when $\omega$ s goes below them. Consequently, Ti-16V based alloys containing 0.3 to $3 \% \mathrm{Al}$ give rise to the $\alpha^{\prime \prime}$ transformation during quenching and alloys containing 5 to $7 \% \mathrm{Al}$ undergo stress-induced martensitic transformation, as was shown in Fig. 7. Probably, alloys with less than $0.3 \% \mathrm{Al}$ and alloys with more than $7 \% \mathrm{Al}$ undergo stress-induced martensitic transformation and slip, respectively. Ti-V-Al ternary alloys containing $3 \%$ Al change the deformation mode from stress-induced martensitic transformation to slip beyond $18 \% \mathrm{~V}$. This may be because the athermal $\omega$ phase is sufficiently reduced by $\mathrm{V}$ when Md goes below room temperature, as shown in Fig. 21.

As mentioned above, tin does not suppress the athermal $\omega$ phase formation so much as Al. Tin, however, really suppresses the athermal $\omega$ phase formation, as can be understood from an X-ray profile of the quenched Ti-16V-4Sn sample shown in Fig. 22 where the athermal $\omega$ phase is not detected. As Fig. 23 schematically shows, $\omega$ s probably decreases more sluggishly in $\mathrm{Ti}-16 \mathrm{~V}$ based Sn-added alloys than it does in the Al-added alloys, compared with the decreases in Md or Ms. The $\beta$ phase

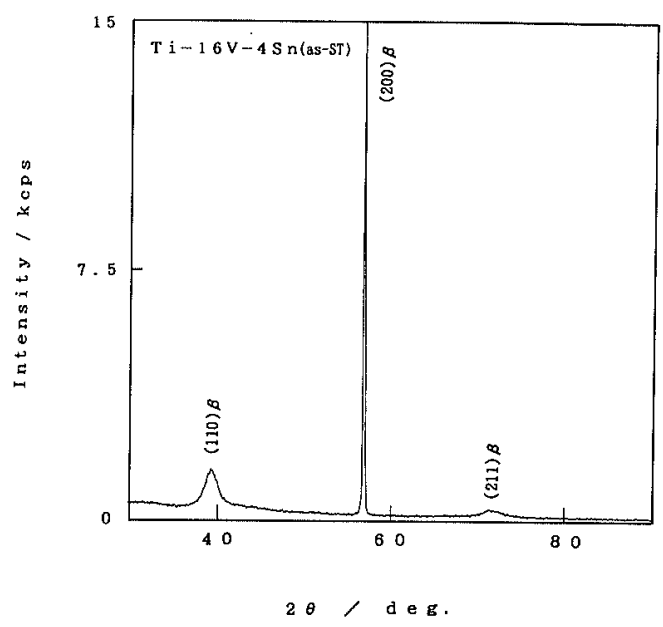

Fig. 22. X-ray profile of the quenched sample of Ti-16V-4Sn.

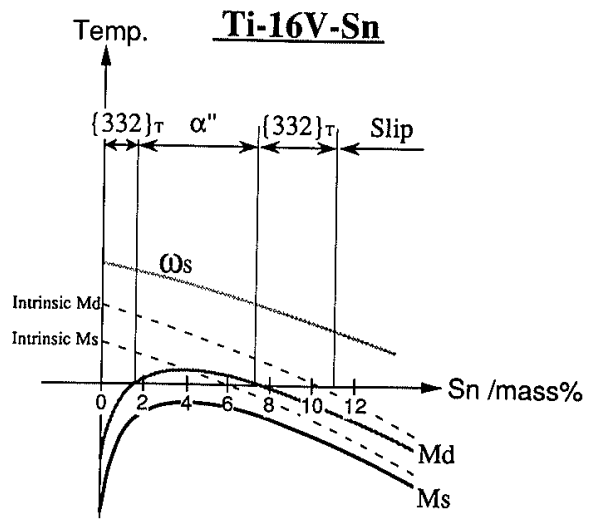

Fig. 23. Schematic changes of Md, Ms, and $\omega s$ with Sn content in Ti-16V-Sn alloy system.

of Sn-added Ti-16V based alloys seems to be still unstable enough for $\{332\}\langle 113\rangle$ twinning when $\mathrm{Md}$ is lowered down to below room temperature. Ti-16V based $\mathrm{Sn}$-added alloys may therefore be expected to undergo stress-induced martensitic transformation at 2 to $6 \%$ $\mathrm{Sn}^{8}{ }^{8}\{332\}\langle 113\rangle$ twinning at about $8 \% \mathrm{Sn}$, and slip at more than $12 \% \mathrm{Sn}$. Since vanadium probably depress $\mathrm{Md}, \mathrm{Ms}$, and $\omega$ s intrinsically in a $\mathrm{Ti}-\mathrm{V}-\mathrm{Sn}$ alloy system as well, the $\mathrm{Sn}$ content dependencies of these temperatures of Ti-16V-Sn alloys in Fig. 23 should be shifted downwards as a whole by the extra $4 \% \mathrm{~V}$, as shown in Fig. 24. Ti-20V-3Sn ${ }^{5)}$ has been reported to deform by $\{332\}\langle 113\rangle$ twinning. It then seems that $\mathrm{Ti}-20 \mathrm{~V}$ based alloys containing up to $3 \% \mathrm{Sn}$ have a $\mathrm{Md}$ below room temperature but are still so unstable to the athermal $\omega$ phase formation that they undergo $\{332\}\langle 113\rangle$ twinning. Stress-induced martensitic transformation, however, occurs in Ti-20V-4Sn, as was shown in Fig. 12. Ti-22V-4Sn is deformed by slip. This may be because both $\mathrm{Md}$ and $\omega \mathrm{s}$ are depressed enough. Presumably, with an increase in Sn content also, alloys may be deformed by slip.

As was understood from Figs. 14 and 15, Ti-16V4Sn-3Al changes the deformation mode from stressinduced martensitic transformation to slip when the contents of each alloying element are increased. These transitions of deformation mode can be interpreted by superposing their effects on $\mathrm{Md}$ and $\omega$, as shown in 


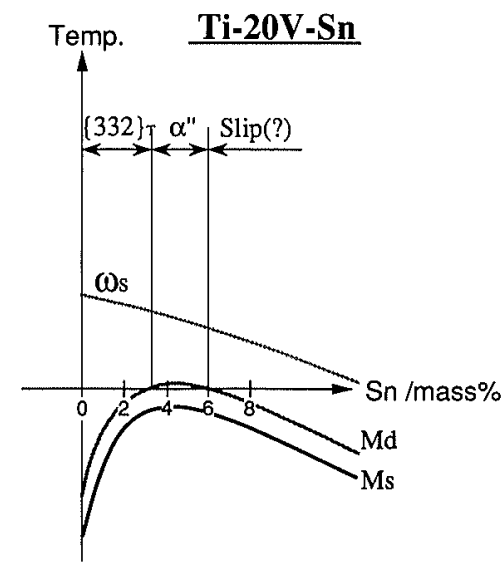

Fig. 24. Schematic changes of $\mathrm{Md}, \mathrm{Ms}$, and $\omega$ s with Sn content in Ti-20V-Sn alloy system. Presumable regions of deformation mode are indicated by question marks (?).

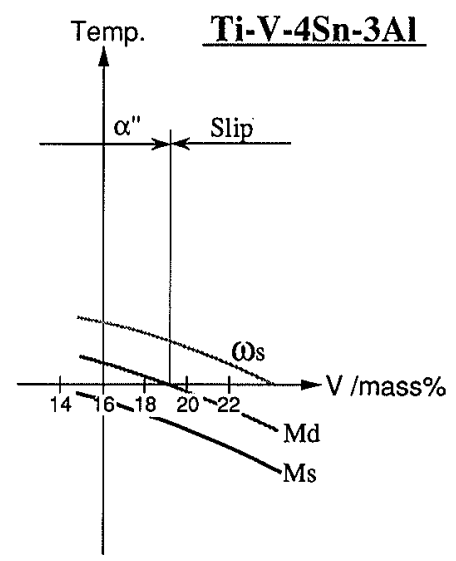

Fig. 25. Schematic changes of Md, Ms, and $\omega$ s with Sn content in $\mathrm{Ti}-\mathrm{V}-4 \mathrm{Sn}-3 \mathrm{Al}$ alloy system.

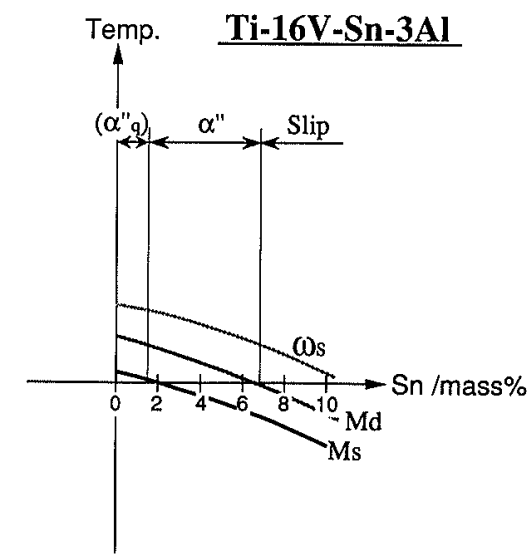

Fig. 26. Schematic changes of Md, Ms, and $\omega$ s with Sn content in $\mathrm{Ti}-16 \mathrm{~V}-\mathrm{Sn}-3 \mathrm{Al}$ alloy system.

Figs. 25, 26, and 27. The $\beta$ phase of $\mathrm{Ti}-16 \mathrm{~V}-4 \mathrm{Sn}-3 \mathrm{Al}$ is fairly stabilized by $3 \% \mathrm{Al}$ and $4 \% \mathrm{Sn}$. A further addition of $\mathrm{V}, \mathrm{Al}$ or $\mathrm{Sn}$ must depress not only $\mathrm{Md}$ but also $\omega \mathrm{s}$ too much to cause $\{332\}\langle 113\rangle$ twinning.

Zirconium does not affect the athermal $\beta$ phase formation behavior substantially. Additions of $\mathrm{Zr}$ simply lower the martensitic transformation temperatures, as shown in Fig. 28. $\mathrm{Zr}$-added $\mathrm{Ti}-16 \mathrm{~V}$ based alloys consequently undergo $\{332\}\langle 113\rangle$ twinning only in the wide range of $\mathrm{Zr}$ content. ${ }^{8)}$

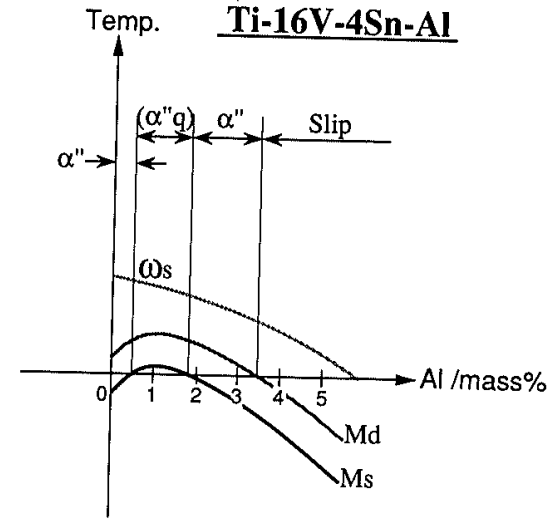

Fig. 27. Schematic changes of Md, Ms, and $\omega s$ with Sn content in $\mathrm{Ti}-16 \mathrm{~V}-4 \mathrm{Sn}-\mathrm{Al}$ alloy system.

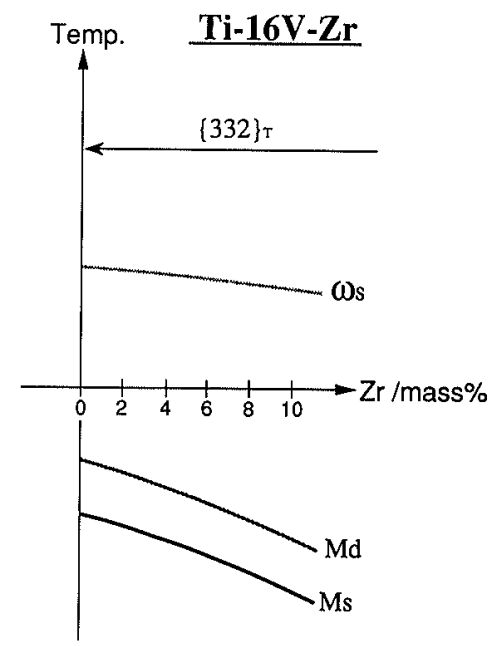

Fig. 28. Schematic changes of $\mathrm{Md}$, $\mathrm{Ms}$, and $\omega$ s with $\mathrm{Zr}$ content in $\mathrm{Ti}-16 \mathrm{~V}-\mathrm{Zr}$ alloy system.

\section{Discussion}

\subsection{Contribution of Athermal $\omega$ Phase to Precipitation Hardening}

It is very important for the occurrence or absence of suppression of martensitic transformation by athermal $\omega$ phase to evaluate its precipitation hardening effect. It is still not clear whether or not the athermal $\omega$ phase contributes the strength and ductility of $\beta$ phase. So, we have discussed this issue through the examinations of tensile properties and hardness of quenched phases including $\alpha^{\prime \prime}$.

Figure 29 shows Vickers hardness of the Ti-V binary alloys vs. V content. The samples containing quenched $\alpha^{\prime \prime}$ phase are indicated by asterisks $\left({ }^{*}\right)$. Moreover, Fig. 30 shows tensile properties $v s$. V content. The tensile specimens were prepared by hot rolling and solution treatment at $1173 \mathrm{~K}$ using button ingots. As is understood from the both figures, the strength of Ti-V alloys first increases up to $14 \%$ and drops at $15 \% \mathrm{~V}$.

Figure 31 shows the change of Vickers hardness after water-quenching with $\mathrm{Al}$ content in the $\mathrm{Ti}-16 \mathrm{~V}-\mathrm{Al}$ alloy system. A small amount of Al addition drastically lowers the hardness of Ti-16V. Maeda and Flower ${ }^{14)}$ also have confirmed the same tendency using $\mathrm{Ti}-15 \mathrm{~V}-\mathrm{Al}$ alloys, and suggested that the reduction in hardness of the $\beta$ phase is attributable to the suppression of athermal $\omega$ 


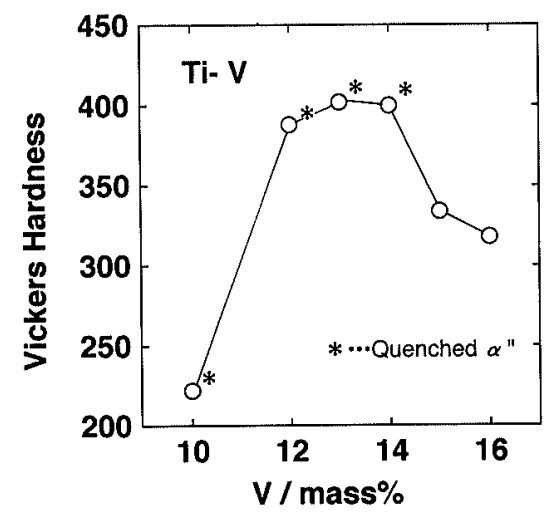

Fig. 29. Change of Vickers hardness with $\mathrm{V}$ content in Ti-V alloy system. The samples containing quenched $\alpha^{\prime \prime}$ phase are indicated by asterisks $\left({ }^{*}\right)$.

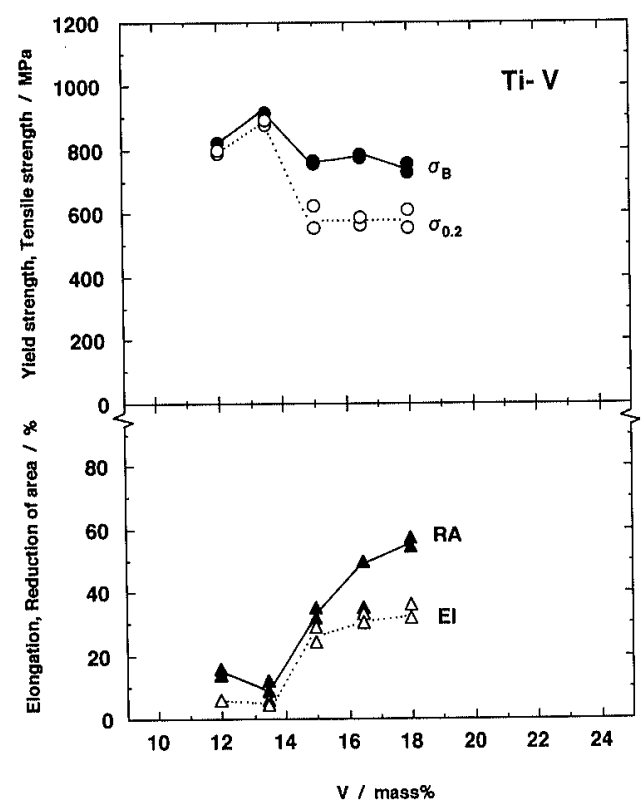

Fig. 30. Tensile properties of Ti-V binary alloys $v s$. V content.

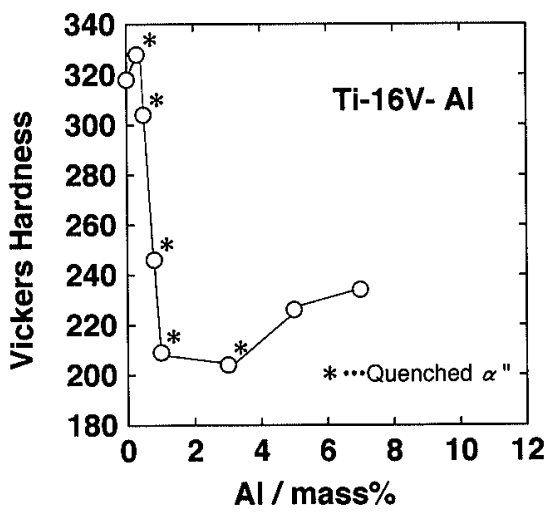

Fig. 31. Change of Vickers hardness with $\mathrm{Al}$ content in Ti-16V-Al alloy system. The samples containing quenched $\alpha^{\prime \prime}$ phase are indicated by asterisks $\left({ }^{*}\right)$.

phase formation. However, the hardness of these Al-added alloys is more or less that of the $\alpha^{\prime \prime}$ phase. At least, the effects of athermal $\omega$ phase on precipitation hardening of $\beta$ phase can not be discussed comparing the hardness of $\beta$ phase with that of quenched or stressinduced $\alpha^{\prime \prime}$ phases. Figure 32 shows tensile properties of Ti-V alloys with $3 \% \mathrm{Al}$ vs. V content. These tensile

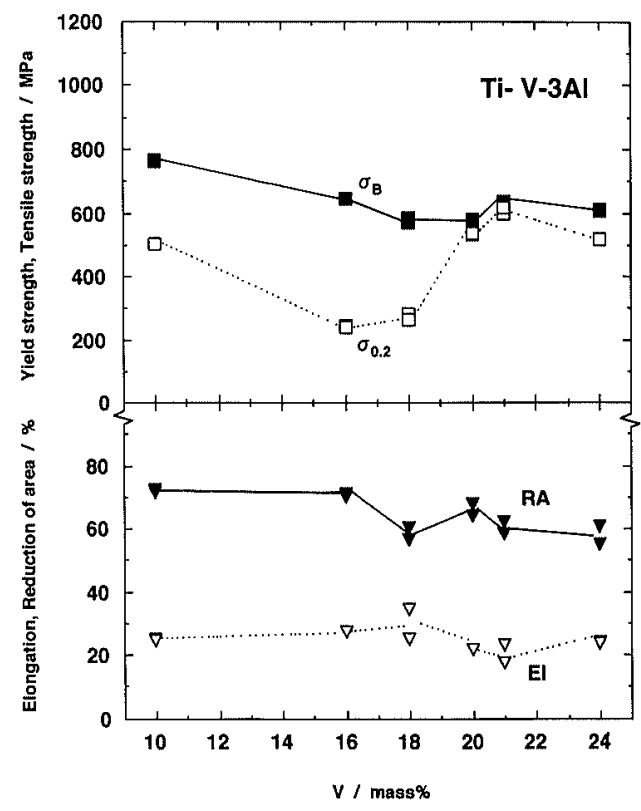

Fig. 32. Tensile properties of Ti-V-3Al alloys $v s$. $\mathrm{V}$ content.

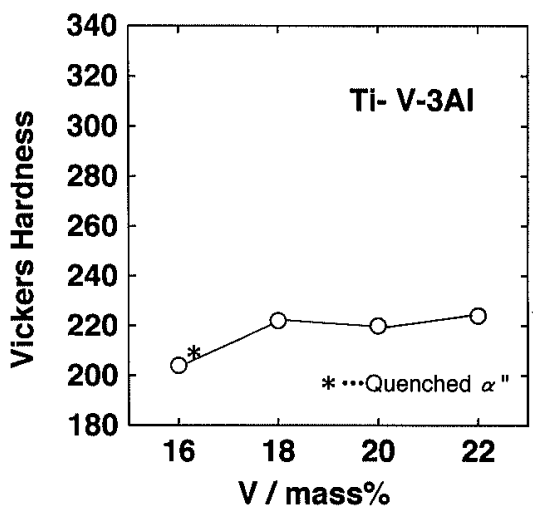

Fig. 33. Change of Vickers hardness with $\mathrm{V}$ content in Ti-V-3Al alloy system. The samples containing quenched $\alpha^{\prime \prime}$ phase are indicated by asterisks $\left({ }^{*}\right)$.

specimens were prepared by hot forging and solution treatment at $1273 \mathrm{~K}$ using button ingots. The alloys containing 10 to $16 \% \mathrm{~V}$ have quenched $\alpha^{\prime \prime}$ phase, and the alloy containing $18 \% \mathrm{~V}$ is strain-transformable. The lattice parameters of orthorhombic $\alpha^{\prime \prime}$ phase has a wide variety of lattice parameters depending on its chemical composition. ${ }^{3,11,18,19)}$ The difference in tensile properties, especially yield strength, of $\alpha^{\prime \prime}$ phase seems to be mainly due to the change of lattice parameters. It is noted that $\mathrm{Ti}-16 \mathrm{~V}-3 \mathrm{Al}$ shows a very low yield strength, compared with $\mathrm{Ti}-16 \mathrm{~V}$. Therefore, the drastic decreases in Vickers hardness of $\mathrm{Ti}-16 \mathrm{~V}-\mathrm{Al}$ in Fig. 31 seem to be exaggerated by the $\alpha^{\prime \prime}$ phase. It is necessary to compare alloys deformed by $\{332\}\langle 113\rangle$ twinning with alloys deformed by slip in order to evaluate the contribution of athermal $\omega$ phase to mechanical properties.

Figure 33 shows Vickers hardness of the Ti-V-3Al alloys $v s$. $\mathrm{V}$ content. As was shown in Fig. 8, Ti-22V-3Al undergoes slip. Comparing this alloy with $\mathrm{Ti}-16 \mathrm{~V}$, $\mathrm{Ti}-16 \mathrm{~V}$ shows a far higher hardness than Ti-22V-3Al. Moreover, Ti-16V has a higher yield strength than Ti-24V-3Al, which is expected to deform by slip as well. Strictly, Ti-16V should have a higher yield strength because it must be deformed by $\{332\}\langle 113\rangle$ twinning 


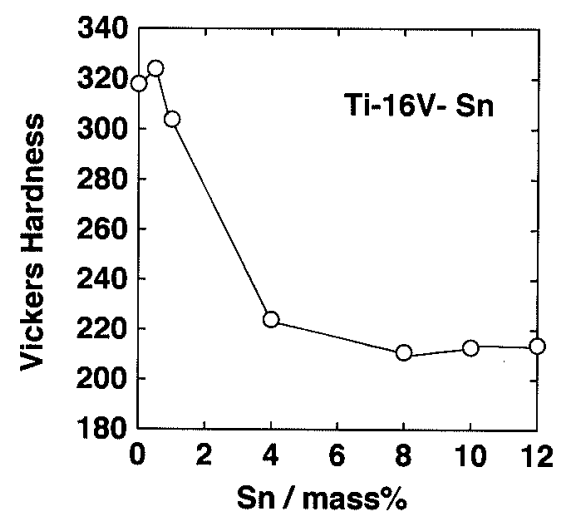

Fig. 34. Change of Vickers hardness with Sn content in Ti-16V-Sn alloy system.

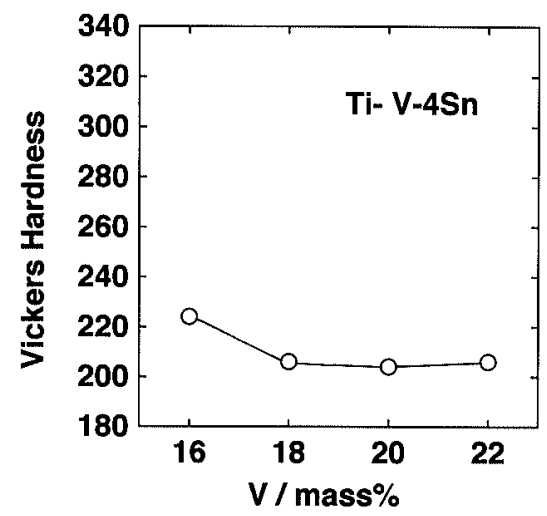

Fig. 35. Change of Vickers hardness with $V$ content in Ti-V-4Sn alloy system.

before yielding. Figures $\mathbf{3 4}$ and $\mathbf{3 5}$ show Vickers hardness of the Ti-16V-Sn and Ti-V-4Sn alloy systems, respectively. Ti-16V-12Sn and Ti-22V-4Sn also have a far lower Vickers hardness than Ti-16V. These alloys containing Al or Sn are more highly alloyed than Ti-16V. From the viewpoint of solution hardening, this tendency is completely reversed. The athermal $\omega$ phase may therefore be expected to play a role in precipitation hardening of $\beta$ phase.

In Fig. 30, the ductility of Ti-V binary alloys clearly increases with increasing $\mathrm{V}$ content beyond $14 \%$. This enhancement of ductility may be due to the suppression of athermal $\omega$ phase caused by increased V. ${ }^{4,15}$ )

\section{Conclusion}

In order to systematically understand the reason some alloys undergo stress-induced martensitic transformation and others $\{332\}\langle 113\rangle$ twinning, we have discussed the effects of $\mathrm{Al}, \mathrm{Sn}$, and $\mathrm{Zr}$ additions on quenched microstructure and the deformation mode in Ti-V based metastable $\beta$ titanium alloys. The results obtained are as follows:

(1) In Ti-V binary $\beta$ alloys, martensitic transformation temperatures $\mathrm{Md}$, Ms, and Mf seem to be considerably depressed out of the intrinsic $\mathrm{V}$ content dependencies by the athermal $\omega$ phase formation beyond about $14 \% \mathrm{~V}$.

(2) In Ti-16V based ternary alloys, a small amount of $\mathrm{Al}$ addition recovers $\mathrm{Ms}$ to give rise to martensitic transformation during quenching. With increasing $\mathrm{Al}$ content, however, all $\beta$ phase can be retained. Since Al sufficiently suppresses the athermal $\beta$ phase formation before $\mathrm{Md}$ reaches room temperature, $\mathrm{Ti}-16 \mathrm{~V}$ based alloys containing 5 to $7 \% \mathrm{Al}$ undergo stress-induced martensitic transformation.

(3) Tin does not suppress the athermal $\omega$ phase formation so much as $\mathrm{Al}$ compared with the depression of $\mathrm{Md}$. The $\beta$ phase is still unstable when $\mathrm{Md}$ of $\mathrm{Ti}-16 \mathrm{~V}-\mathrm{Sn}$ alloys reaches room temperature. Therefore, Ti-16V based Sn-added alloys change the deformation mode from stress-induced martensitic transformation to slip via $\{332\}\langle 113\rangle$ twinning.

(4) The deformation mode of Ti-V-Al-Sn alloys can be interpreted by superposing the effects of $\mathrm{V}, \mathrm{Al}$, and Sn.

(5) Zirconium depresses martensitic transformation temperatures and $\mathrm{Ti}-14 \mathrm{~V}-6 \mathrm{Zr}$ undergoes stress-induced martensitic transformation. $\mathrm{Ti}-16 \mathrm{~V}$ based $\mathrm{Zr}$-added alloys undergo $\{332\}\langle 113\rangle$ twinning in the wide range of $\mathrm{Zr}$ content because the athermal $\omega$ phase formation is rarely suppressed by $\mathrm{Zr}$.

\section{REFERENCES}

1) H. Ohyama, T. Nishimura and Y. Ashida: Advanced MaterialsNew Process and Reliability-, ed. by T. Kishi, N. Takeda and Y. Kagawa, SAMPE, (1993), 1790.

2) H. Ohyama, H. Nakamori, Y. Ashida and T. Maki: ISIJ Int., 32 (1992), 222.

3) J. C. Williams: Titanium Science and Technology, ed. by R. I. Jaffee and H. M. Burte, AIME, Plenum Press, New York, NY, (1973), 1433.

4) S. Hanada and O. Izumi: Metall. Trans. A, 17A (1986), 1409.

5) S. Hanada and O. Izumi: Metall. Trans. A, 18A (1987), 265.

6) M. Oka and Y. Taniguchi: J. Jpn. Inst. Met., 42 (1978), 814 (in Japanese).

7) N. E. Paton and J. C. Williams: Proc. of Second Int. Conf. on Strength of Metals and Alloys, ASM, Metals Park, OH, (1971), 108.

8) S. Ishiyama, S. Hanada and O. Izumi: ISIJ Int., 31 (1991), 807.

9) J. C. Williams, D. de Fontaine and N. E. Paton: Metall. Trans., 4 (1973), 2701.

10) M. Ikeda, S. Y. Komatsu, T. Sugimoto and K. Kamei: Sixth World Conf. on Titanium, ed. by P. Lacombe, R. Tricot and G. Beranger, Les Editions de Physique, Paris, (1989), 313.

11) H. M. Flower, R. Davis and D. R. F. West: Titanium and Titanium Alloys, Scientific and Technological Aspects, ed. by J. C. Williams and A. F. Belov, Plenum Press, New York, NY, (1982), 1703.

12) M. Oka, C. S. Lee and K. Shimizu: Metall. Trans., 3 (1972), 37.

13) T. Maeda and H. M. Flower: Sixth World Conf. on Titanium, ed. by $\mathbf{P}$. Lacombe, R. Tricot and G. Beranger, Les Editions de Physique, Paris, (1989), 1629.

14) T. Maeda and H. M. Flower: Sixth World Conf. on Titanium, ed. by P. Lacombe, R. Tricot and G. Beranger, Les Editions de Physique, Paris, (1989), 1589.

15) S. Hanada, A. Takemura and O. Izumi: Trans. JIM., 23 (1982), 507.

16) S. Komatsu, M. Ikeda, T. Sugimoto, K. Kamei and K. Inoue: J. Jpn. Inst. Met., 55 (1991), 491 (in Japanese).

17) M. Ikeda, S. Komatsu, T. Sugimoto, K. Kamei and K. Inoue: Tetsu-to-Hagané, 80 (1994), 866 (in Japanese).

18) R. Davis, H. M. Flower and D. R. F. West: J. Mater. Sci., 14 (1979), 712.

19) H. Sasano, T. Suzuki, O. Nakano and H. Kimura: Titanium '80 Science and Technology, ed. by $K$. Kimura and $O$. Izumi, TMS-AIME, Warrendale, Penn., (1980), 717. 